\section{Self-Expanding Esophageal Stents and Neoadjuvant Therapy}

\section{TO THE EDITORS:}

We were concerned to read that Langer and colleagues advocate self-expanding metal or plastic stents as a means to allow adequate oral nutrition while their patients received neoadjuvant therapy despite over a third (34\%) of the cases having complications without any improvement in nutritional markers.

The authors report significant improvements in dysphagia scores following the deployment of the stent. In our experience, patients with dysphagia secondary to esophageal tumors have improvement in their swallow during and following a course of neoadjuvant chemotherapy or chemoradiotherapy. This is a beneficial side effect and would have affected the dysphagia scores collected by Langer and colleagues. This could explain the high rate of migration the authors experienced (32\%). The authors also report a significant number of complications secondary to the migrated stent including small bowel perforation, bolus obstruction, esophagobronchial fistulae, and aortic wall erosion.

Of equal concern, only 20 of 38 patients (53\%) went onto have their intended resection following neoadjuvant therapy. This contrasts with our unit data where there is a $94 \%$ resection rate following neoadjuvant chemotherapy. It has previously been reported that there is a deleterious survival effect in patients treated with a palliative esophageal stent, and the poor resection rate may be a consequence of this effect. ${ }^{1,2}$

Although the authors have an interesting treatment concept, they should be wary of recommending an intervention with such a high rate of complications without proof of patient benefit.

M. Webb, MBBS, MRCS, S. M. Griffin, MD, FRCS, and J. Shenfine, PhD, FRCS

Northern Oesophago-Gastric Cancer Unit, Royal Victoria Infirmary, Newcastle Upon Tyne, UK

e-mail: s.m.griffin@ nuth.nhs.uk

Published Online: 5 June 2010

(C) Society of Surgical Oncology 2010

\section{REFERENCES}

1. Shenfine J, McNamee P, Steen N, Bond J, Griffin SM. A randomized controlled clinical trial of palliative therapies for patients with inoperable esophageal cancer. Am J Gastroenterol. 2009;104:1674-85.

2. Dallal HJ, Smith GD, Grieve DC, Ghosh S, Penman ID, Palmer KR. A randomized trial of thermal ablative therapy versus expandable metal stents in the palliative treatment of patients with esophageal carcinoma. Gastrointest Endosc. 2001;54:549-57. 